\title{
ECSIT is an evolutionarily conserved intermediate in the Toll/IL-1 signal transduction pathway
}

\author{
Elizabeth Kopp, Ruslan Medzhitov, James Carothers, Changchun Xiao, Iris Douglas, \\ Charles A. Janeway, and Sankar Ghosh ${ }^{1}$
}

Section of Immunobiology and Department of Molecular Biophysics and Biochemistry,

Howard Hughes Medical Institute (HHMI), Yale University School of Medicine, New Haven, Connecticut 06520 USA

\begin{abstract}
Activation of NF-кB as a consequence of signaling through the Toll and IL-1 receptors is a major element of innate immune responses. We report the identification and characterization of a novel intermediate in these signaling pathways that bridges TRAF6 to MEKK-1. This adapter protein, which we have named ECSIT (evolutionarily conserved signaling intermediate in Toll pathways), is specific for the Toll/IL-1 pathways and is a regulator of MEKK-1 processing. Expression of wild-type ECSIT accelerates processing of MEKK-1, whereas a dominant-negative fragment of ECSIT blocks MEKK-1 processing and activation of NF-кB. These results indicate an important role for ECSIT in signaling to NF-кB and suggest that processing of MEKK-1 is required for its function in the Toll/IL-1 pathway.
\end{abstract}

[Key Words: Signal transduction pathway; immune response; signaling intermediate; Toll pathway; NF-кB]

Received May 25, 1999; revised version accepted July 6, 1999.

The Toll family of proteins is comprised of signaling receptors containing a region of homology known as the Toll/IL-1 receptor (TIR) domain. There are now many receptors and one cytoplasmic adaptor protein containing TIR domains. In mammals, the receptors include five human Tolls (TLR1, TLR2, TLR3, TLR4, and TLR5) (Medzhitov et al. 1997; Chaudhary et al. 1998; Rock et al. 1998), the type I IL-1 receptor (IL-1R1) (Sims et al. 1988), the IL-1 receptor accessory protein (IL-1RAcP) (Greenfeder et al. 1995), and the IL-18 receptor (IL-18R) (Torigoe et al. 1997). The functions of the signaling pathways resulting from activation of these receptors are likewise related; they all relay information about infection by activating the transcription factors NF- $\mathrm{kB}$ and AP-1, which in turn up-regulate transcription of genes involved in immune responses. Until recently, few of the participating signaling molecules in these important pathways had been identified; however, now it appears that the IL-1 receptor and Toll use common intermediate proteins leading to the activation of NF-кB (for review, see Kopp and Medzhitov 1999). For example, Toll, IL-1R1, and IL$18 \mathrm{R}$ all interact with MyD88, a cytoplasmic adaptor protein that also contains a TIR domain. This interaction occurs via homophilic binding of the TIR domains of MyD88 and the receptor upon ligand engagement or receptor activation. After ligand binding, IL-1 receptor associated kinase (IRAK), a serine/threonine kinase, is re-

${ }^{1}$ Corresponding author.

E-MAIL sankar.ghosh@yale.edu; FAX (203) 727-1764. cruited to the receptor complex by binding to MyD88 and becomes autophosphorylated. Another adaptor, TRAF6, then interacts with IRAK (for review, see Kopp and Medzhitov 1999).

Downstream of TRAF6, the mechanism by which NF$\kappa \mathrm{B}$ activation is achieved has recently been elucidated. NF- $\kappa \mathrm{B}$ is the general term given to homo- or heterodimers of the Rel family of proteins, which pre-exist in the cytoplasm of most cells in an inactive state by virtue of their interaction with a class of inhibitory proteins called IкBs (for review, see Ghosh et al. 1998). Upon appropriate cellular stimulation, ІкBs are specifically phosphorylated and degraded through a ubiquitin/proteasome-dependent mechanism. The kinases responsible for phosphorylating ІкB are known as the IкB kinases, IKK-1 and IKK-2 (for review, see May and Ghosh 1998), and they form a large multiprotein complex that also contains scaffolding proteins such as IKAP and NEMO(IKK $\gamma$ ) (Cohen et al. 1998; Rothwarf et al. 1998; Yamaoka et al. 1998). The IKKs themselves are believed to be activated through phosphorylation by a kinase belonging to the MAP kinase kinase kinase (MAPKKK) family. Candidates for this kinase include NIK (NF-кB inducing kinase) and MEKK-1 (mitogen-activated protein kinase/ERK kinase kinase-1), because each of these kinases can activate NF- $\mathrm{kB}$ through phosphorylation and activation of the IKKs. TRAF6 is capable of binding NIK and may therefore activate NF- $\kappa$ B via a NIK-IKK pathway. MEKK-1-mediated activation of NF-кB by TRAF6, however, has never been demonstrated. 
The Toll signaling pathway is conserved from Drosophila to humans and functions in innate immune responses (Belvin and Anderson 1996; Medzhitov et al. 1998). There are several Drosophila Toll proteins and upon signaling an adapter protein, Tube, is recruited to the membrane (Galindo et al. 1995; Towb et al. 1989). Other components in the pathway are homologous to the mammalian proteins: Pelle, a serine/threonine kinase is homologous to IRAK, and Drosophila TRAF6 was recently cloned (Liu et al. 1999; R. Medzhitov and C. Janeway, unpubl.). Cactus, the ІкB homolog, is phosphorylated and degraded in response to Toll signaling allowing the translocation of a Rel protein (Dorsal or Dif) to the nucleus (Drier and Steward 1997). Activation of Rel proteins in these pathways leads to the production of antimicrobial peptides (for review, see Hoffmann et al. 1996) against specific types of pathogens, indicating that Drosophila must be able to discriminate between different types of infection (Lemaitre et al. 1997). Like the mammalian system, however, it is unclear how such discrimination is achieved because although the receptors are different, the known cytosolic signaling molecules are common to these pathways.

TRAF6 is a member of the TRAF family of adaptor proteins (for review, see Arch et al. 1998). The TRAFs (TNF-receptor associated factors) were first described as proteins that are recruited to the tumor necrosis factor (TNF) receptors during signaling (Rothe et al. 1994). There are currently six TRAF proteins known. Each TRAF, with the exception of TRAF1, has an amino-terminal region containing ring and zinc fingers and a carboxy-terminal conserved region known as the TRAF domain bearing an amino-proximal coiled-coil sequence, TRAF-N (Arch et al. 1998), and an $\sim 170$ amino acid carboxy-proximal domain, TRAF-C. TRAF1 has a similar domain structure as the other TRAFs except it lacks an amino-terminal ring finger domain. TRAF6 shares $\sim 30 \%$ identity in the TRAF-C domain with TRAFs 1-5, which makes it the most divergent TRAF known (Cao et al. 1996b; Ishida et al. 1996). Overexpression of TRAF2, TRAF5, and TRAF6 leads to activation of NF- $\kappa$ B and AP-1 (Arch et al. 1998); however, TRAF6 is otherwise functionally distinct from the other TRAFs. Whereas TRAFs $1-5$ are recruited to the TNF receptor complex and activate NF- $\kappa \mathrm{B}$ via the kinase RIP (receptor interacting protein) (Arch et al. 1998), TRAF6 participates in IL-1 receptor and Toll activation of NF- $\mathrm{B}$ by interacting with the kinase IRAK (Cao et al. 1996b).

Because the mechanism by which expression of TRAF6 activates both NF- $\kappa$ B and AP-1 was unclear, we were interested in identifying TRAF6-interacting proteins that might potentially connect TRAF6 with downstream signaling elements. In this paper we present the cloning and characterization of a novel TRAF6 binding protein, ECSIT (evolutionarily conserved signaling intermediate in Toll pathways). ECSIT interacts with the conserved TRAF domain of TRAF6 and is an intermediate in the Toll signaling pathway. ECSIT also interacts with the MAP kinase kinase kinase family member, MEKK-1, thereby linking TRAF6 to a kinase that can activate both NF-кB and AP-1. ECSIT is involved in the regulation of MEKK-1 because expression of ECSIT promotes the processing of full-length MEKK-1. We have also cloned the ECSIT homolog in Drosophila and have demonstrated that it binds Drosophila TRAF6 and induces the transcription of host defense genes in insect cells. ECSIT is therefore an important conserved component of ancient host defense pathways.

\section{Results}

Cloning of ECSIT by yeast two-hybrid screening

To identify novel proteins in the conserved TIR pathway, we used the yeast two-hybrid system to screen a mouse liver library with full-length murine TRAF6. Multiple screenings yielded a unique cDNA of $1.2 \mathrm{~kb}$, whose gene product interacted with TRAF6 in this assay (data not shown). The entire cDNA was used to screen a multiple tissue Northern blot by hybridization (Fig. 1A). One transcript of $\sim 1.6 \mathrm{~kb}$ was present in all tissues examined. We used the same cDNA to screen pre-B-cell and mouse liver cDNA libraries and cloned three fulllength $1.6-\mathrm{kb}$ cDNAs. The proteins encoded by these cDNAs differ in their carboxyl termini, and sequencing of these cDNAs revealed that they were alternative splice variants (Fig. 1B; data not shown). The transcript with the longest open reading frame was cloned from the mouse liver library and corresponded exactly to the original cDNA from yeast two-hybrid screening but contained an additional 400 nucleotides at the $5^{\prime}$ end including an in-frame stop codon. This cDNA encodes a protein of 435 amino acids (the original cDNA lacked the first 20 amino acids) with no homology to any known protein (Fig. 1C). The putative amino acid sequence of this protein also lacks any known protein domains. However, there are sequences in the EST databases corresponding to homologs in human, rat, and Drosophila. Using cDNA from Schneider insect cells, we have also cloned the Drosophila homolog of ECSIT, which is $\sim 31 \%$ identical to the murine protein (Fig. 1C).

\section{ECSIT interacts with TRAF6}

TRAF6 is a member of a family of signaling proteins; therefore, it was possible that ECSIT might interact with other TRAFs. Of the six TRAFs known, TRAF2, and TRAF5 are functionally similar to TRAF6 in that they activate NF- $\kappa$ B and AP-1 (for review, see Arch et al. 1998). To determine if ECSIT interacts specifically with TRAF6, we performed immunoprecipitation experiments from 293 cells and assayed by immunoblotting for the presence of endogenous TRAF2, TRAF5, or TRAF6. These experiments were performed with transfected HAtagged ECSIT because we have been unable to raise effective antibodies against ECSIT. Endogenous TRAF2, TRAF5, and TRAF6 were assayed with specific antibodies. As expected, the HA-tagged ECSIT immunoprecipitated endogenous TRAF6, and although TRAF2 and 


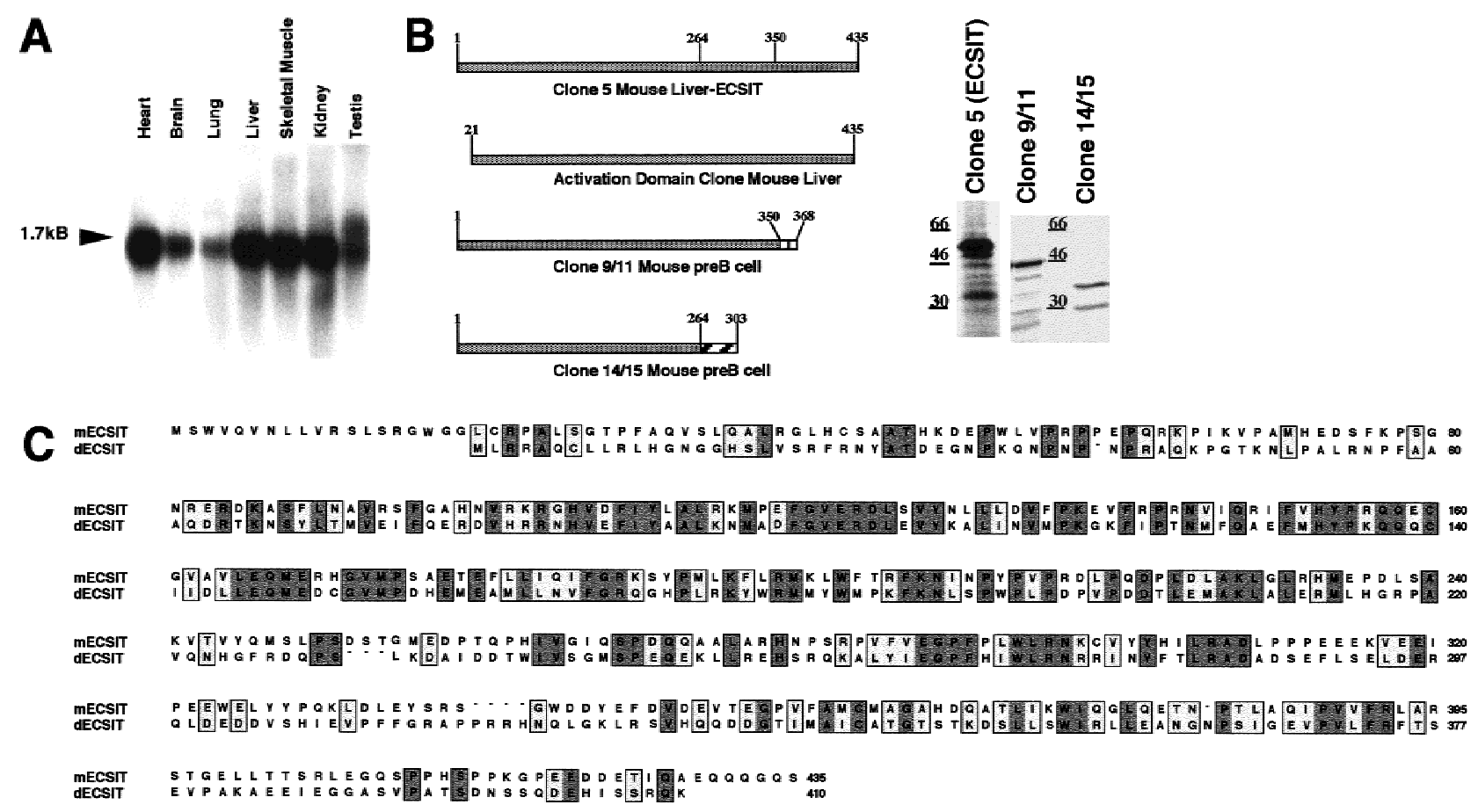

Figure 1. Sequence and expression of ECSIT. $(A)$ Multiple tissue Northern blot. The clone retrieved from yeast two-hybrid assay was labeled with ${ }^{32} \mathrm{P}$ and used to probe a murine blot containing mRNA from the indicated tissues. (B) Clones identified in hybridization screening of murine cDNA libraries. The yeast two-hybrid activation domain clone (amino acids 21-435) is compared with ECSIT retrieved from a mouse liver cDNA library (clone 5) (Clontech) and to clones retrieved in a murine pre-B cell-library (left). The alternate carboxy-terminal sequences in the 9/11 and 14/15 cDNAs are represented by the hatched boxes. In vitro translation products of the three cDNAs are shown (right). $(C)$ Comparison of sequences of murine ECSIT (mECSIT) and dECSIT. Identical and similar amino acids are indicated by shading.

TRAF5 were present in the lysate, they were not coprecipitated (Fig. 2A). Even when we overexpressed FLAGtagged TRAF proteins along with ECSIT, we were unable to immunoprecipitate TRAF2 or TRAF5 (data not shown).

To determine the sites of interaction between TRAF6 and ECSIT, we performed immunoprecipitation and glutathione $S$-transferase (GST) pull-down assays with deletion mutants of each of these proteins (Fig. 2B,C). FLAG epitope-tagged amino-terminal deletions of ECSIT were transfected with full-length TRAF6 and immunoprecipitated using an anti-TRAF6 polyclonal antibody. TRAF6 efficiently precipitated the amino acid 21-435 mutant protein that corresponded to the original clone isolated by the yeast two-hybrid assay. In addition, TRAF6 precipitated a smaller mutant protein comprised of amino acids 137-435 (Fig. 2B). Proteins containing larger amino-terminal deletions beginning at amino acid 234 or farther downstream did not coimmunoprecipitate with TRAF6. Therefore, the amino-terminal region of ECSIT between amino acids 137 and 234 is required for TRAF6 binding.

To determine whether TRAF6 could interact with ECSIT in vitro, we performed GST pull-down assays with in vitro-translated mutants of TRAF6. Because TRAF6 has an obvious domain structure, we made TRAF6 mutants containing all or some of its domains and in vitro-translated them in the presence of $\left[{ }^{35} \mathrm{~S}\right] \mathrm{me}$ thionine. Full-length GST-ECSIT does not express well in bacteria; therefore, we used a GST fusion protein of the original clone obtained by yeast two-hybrid screening that lacks 20 amino acids at the amino terminus for this assay. (Fig. 2C). The amino-terminal region of TRAF6 including the ring and zinc fingers did not coprecipitate in this assay. However, full-length TRAF6 (and to a lesser extent the TRAF domain of TRAF6), did interact with ECSIT. These results indicate that TRAF6 and ECSIT probably interact directly with one another.

\section{ECSIT participates in the Toll signaling pathway}

To see if expression of ECSIT could activate NF-кB, we transfected 293 cells with ECSIT and assayed NF-кB activity using a $\kappa \mathrm{B}$-dependent luciferase reporter. As shown in Figure 3A, ECSIT activates NF- $\mathrm{BB}$ in a dosedependent manner. We also tested deletion mutants of ECSIT for their ability to activate NF- $\mathrm{BB}$ (Fig. 3B). Only ECSIT constructs containing amino-terminal sequences between amino acids 21 and 137 were functional in this assay (Fig. 3B).

To determine whether ECSIT was a signaling molecule required for TRAF6-dependent NF- $\mathrm{kB}$ activation, we expressed a deletion mutant of ECSIT in 293 cells and tested its ability to inhibit NF- $\mathrm{BB}$ activity induced by 
Kopp et al.

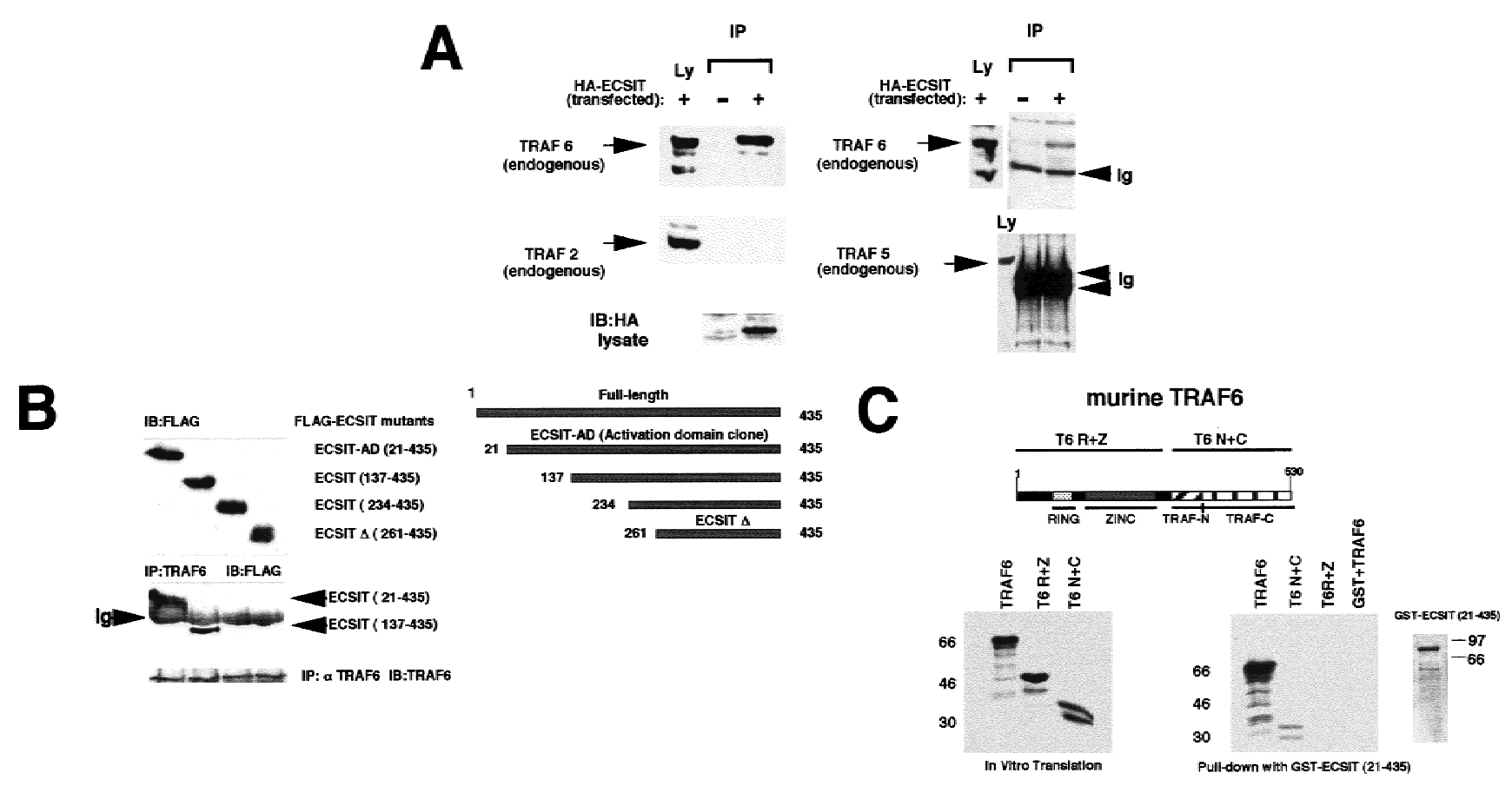

Figure 2. ECSIT specifically interacts with TRAF6. (A) Coprecipitation of endogenous TRAF6 with transfected ECSIT. Lysates were prepared from untransfected and HA-tagged ECSIT-transfected 293 cells (left) and immunoprecipitated overnight with $20 \mu \mathrm{l}$ of anti-HA monoclonal antibody and $25 \mu \mathrm{l}$ of protein G-Sepharose. Sepharose beads were centrifuged and washed extensively, and bound endogenous protein was removed from the beads by addition of SDS-containing running buffer and boiling. Samples were divided in two, separated by SDS-PAGE, and immunoblotted with either an antibody to TRAF6 or an antibody to TRAF2. Lysates (Ly) that had not been immunoprecipitated were also assayed for the presence of transfected ECSIT (HA antibody) or for the presence of endogenous TRAF2 or TRAF6. COS cells (right) were assayed similarly for the ability of HA-ECSIT to immunoprecipitate TRAF5 (antibody from Santa Cruz). (IP) Immunoprecipitation; (Ly) lysates; (Ig) immunoglobulin. (B) In vivo mapping of the TRAF6 binding site on ECSIT. 293 cells were transfected with amino-terminal Flag epitope-tagged deletion constructs of ECSIT (schematic shown at right) and immunoprecipitated (IP) with TRAF6 antibody. Unprecipitated lysates were separated by SDS-PAGE (top) and assayed by immunoblotting (IB) with an antibody to Flag (M5). Immunoprecipitates were washed, denatured with SDS running buffer, boiled, and analyzed by SDS-PAGE (bottom). Membrane was blotted in Flag (M5) antibody to reveal interacting proteins. As a control the immunoprecipitated blot was reprobed with an antibody to TRAF6. (Ig) Immunoglobulin; (ECSIT-AD) ECSIT 21-435 originally cloned from yeast twohybrid library; (ECSITA) ECSIT 261-435 deletion mutant. (C) In vitro mapping of the ECSIT binding site on TRAF6. A GST fusion protein of ECSIT (21-435) was prepared in bacteria and incubated with ${ }^{35}$ S-labeled in vitro translation products of TRAF6 including full-length TRAF6, the amino-terminal ring and zinc fingers of TRAF6 (T6 R+Z), and the carboxy-terminal TRAF domain (T6 N+C). Proteins binding to GST-ECSIT (21-435) were bound to glutathione-Sepharose beads, washed, and analyzed by PAGE (right). Two micrograms of GST alone was also incubated with full-length TRAF6 (GST+TRAF6) as a control.

members of the Toll signaling pathway. Because ECSIT lacks recognizable functional domains, we used a deletion construct of ECSIT (amino acids 261-435) that did not activate NF-kB (referred to as ECSIT $\Delta$ ) as a dominant-negative inhibitor of signaling (Fig. 3B). A constitutively active human Toll 4 construct (CD4/TLR4) has been shown to activate NF-кB when expressed in cells (R. Medzhitov, unpubl.). We found that ECSIT $\Delta$ was able to inhibit NF- $\kappa \mathrm{B}$ activation by the transfected CD4/ TLR4 (Fig. 4A), consistent with the model that ECSIT is involved in Toll signaling. In both TNF receptor and TIR signaling, a serine/threonine kinase propagates the signal from the receptor to a downstream TRAF adapter molecule. Kinases known to be directly involved in TRAF signaling at this level include RIP, which binds TRAF2 (Stanger et al. 1995; Takeuchi et al. 1996), and IRAK, which binds TRAF6 (Muzio et al. 1997). Because wild-type IRAK weakly activates NF-кB, we constructed a constitutively active IRAK mutant that is targeted to the membrane. The expression of this construct yields significantly more ( 10-fold) NF-kB activity than its wild-type counterpart (R. Medzhitov, unpubl.). The ECSIT $\Delta$ mutant inhibited IRAK-mediated activation of NF- $\mathrm{BB}$ but did not inhibit RIP at the same concentrations suggesting that ECSIT does not participate in the TNFRRIP signaling pathway (Fig. 4B).

\section{ECSIT is involved in MEKK-1 activation of NF-ÏB}

The TRAF proteins have been shown to be the divergence point between the activation of NF-кB and activation of AP-1 (Liu et al. 1996; Song et al. 1979; Muzio et al. 1998). Downstream of the TRAFs, a kinase of the MAPKKK family has been suggested to propagate the signal by phosphorylating and activating other kinases. When overexpressed, the MAPKKK protein NIK (NF-кB 

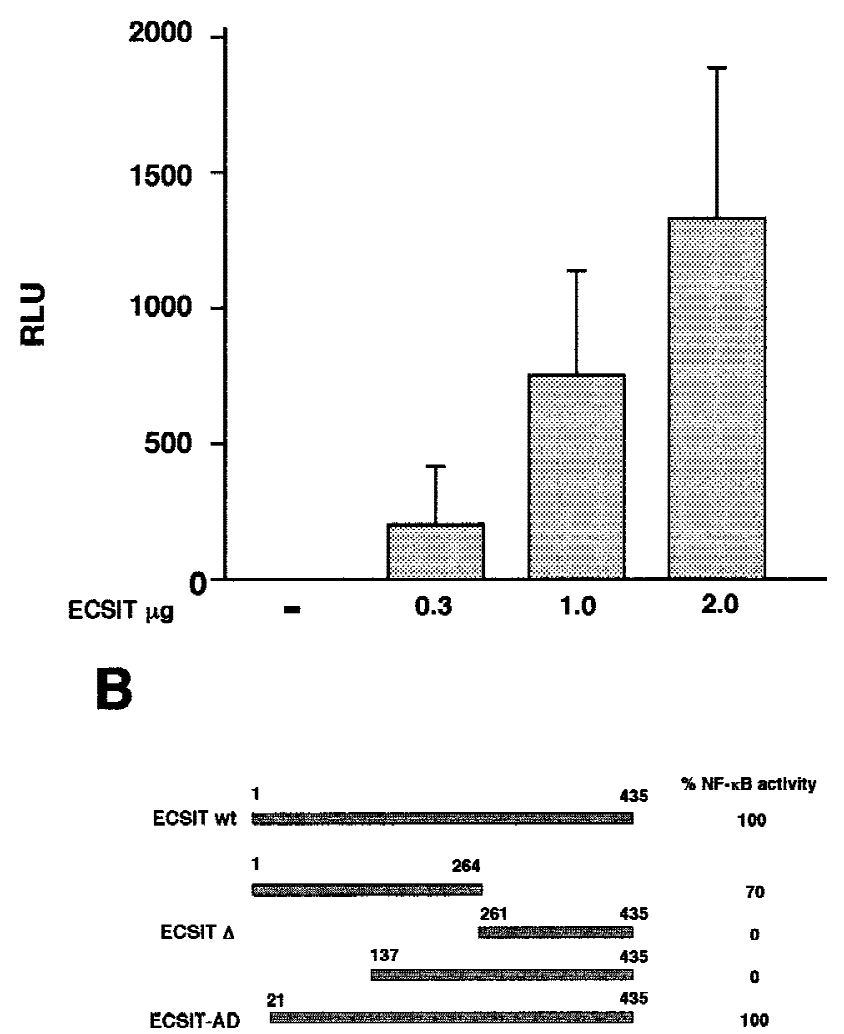

Figure 3. Activation of NF-кB by overexpression of ECSIT. $(A)$ 293 cells stably transfected with an NF-кB / luciferase reporter gene $(293 \kappa \mathrm{B}-\mathrm{LUC})$ were transiently transfected with increasing amounts of ECSIT. Twenty-four hours after transfection, cells were lysed and assayed for luciferase activity. Background (untransfected) was subtracted, and values shown are per microgram of total protein in each sample. (B) $293 \mathrm{kB}-\mathrm{LUC}$ cells were transfected with $1 \mu \mathrm{g}$ of the indicated ECSIT mutants. Twentyfour hours after transfection, cells were lysed and assayed for luciferase activity relative to activity achieved with the ECSIT wild-type protein (ECSITwt). ECSIT (261-435) is referred to as ECSIT $\Delta$. ECSIT-AD corresponds to the original clone isolated from the yeast two-hybrid library.

inducing kinase) (Malinin et al. 1997) activates NF-кB but not AP-1 (Song et al. 1997) and may be one such downstream kinase. It is capable of binding all of the TRAFs, and a kinase-defective mutant of NIK inhibits NF- $\mathrm{KB}$ activation by TRAF2, TRAF5, and TRAF6 (Malinin et al. 1997; Song et al. 1997). But unlike NIK, another kinase of the MAPKKK family, ASK-1, appears to direct signaling exclusively to AP-1 (Nishitoh et al. 1998) even though it can be coprecipitated with many TRAFs including TRAF6. However the MAPKKK MEKK-1 can activate both NF- $\mathrm{KB}$ and AP-1, although it has not been shown to interact directly with any of the TRAFs (Natoli et al. 1997).

Because NIK and MEKK-1 have both been implicated in the signaling cascade to NF- $\mathrm{kB}$ through the TRAF proteins, we tested the ability of our dominant-negative ECSIT construct to inhibit these kinases in an NF-кBdependent reporter assay. The ECSIT $\Delta$ dominant-negative mutant strongly inhibited NF-кB activation by MEKK-1 but not by NIK (Fig. 5A) suggesting that ECSIT is specifically involved in MEKK-1 signaling. MEKK-1 also efficiently activates the transcription factor AP-1; therefore, we tested ECSIT $\Delta$ in a reporter assay for AP-1 activity and found that this ECSIT mutant also strongly inhibited MEKK-1 activation of AP-1 (Fig. 5A). As re-

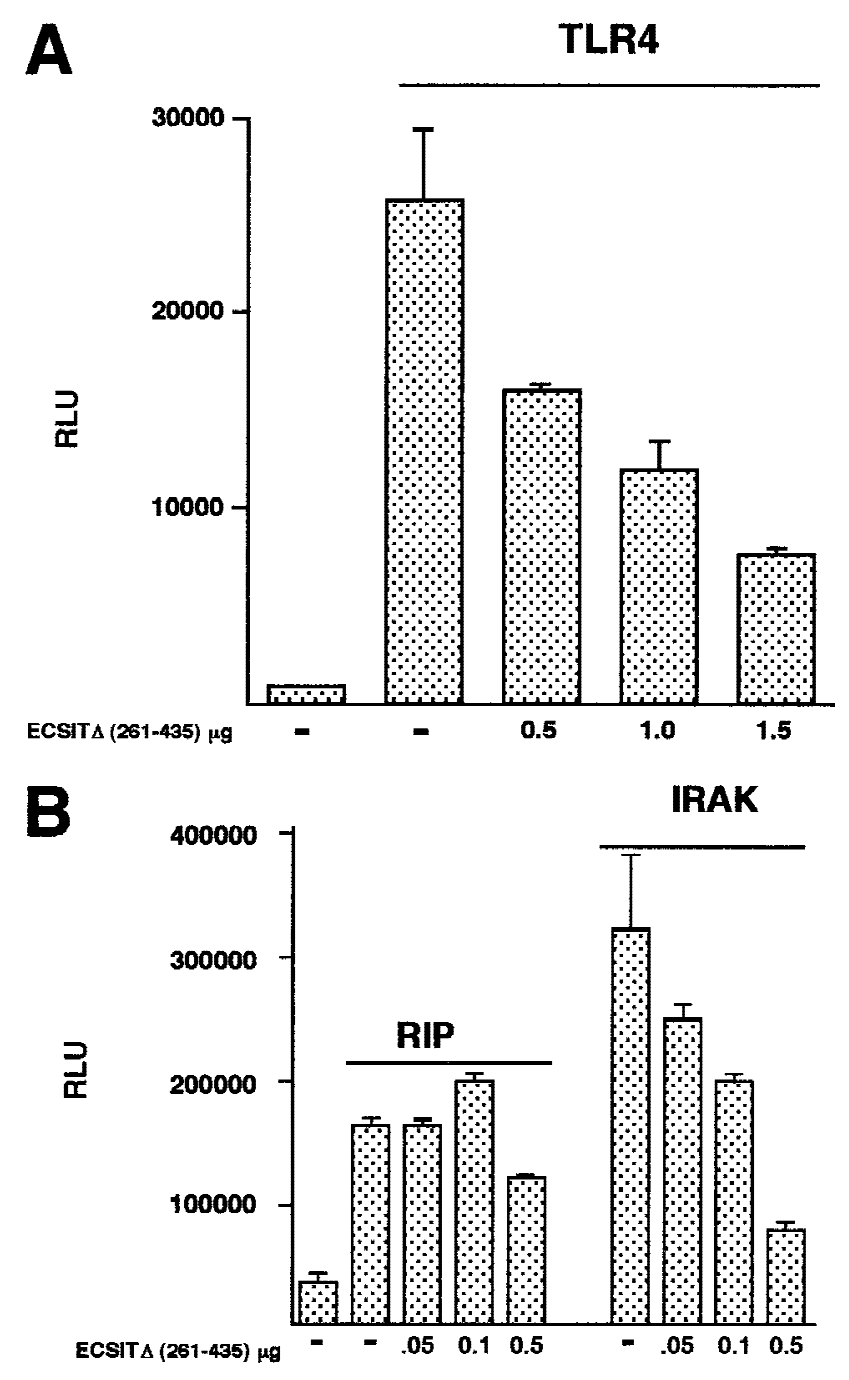

Figure 4. Inhibition of Toll and IL-1 receptor pathway members by a dominant-negative ECSIT mutant. (A) 293kB-LUC cells were transfected with $0.5 \mu \mathrm{g}$ of the constitutively active human Toll mutant CD4/TLR4 and either vector control DNA $(-)$ or indicated amounts of ECSIT $\Delta$. DNA concentration in all transfections was equilibrated to $2 \mu \mathrm{g}$ with vector. Twenty-four hours after transfection, lysates were assayed for luciferase activity. (B) $293 \mathrm{\kappa} B-$ LUC cells were transfected with the indicated DNAs and assayed as above. The different constructs were RIP wild type, IRAK cytoplasmic domain fused to CD4 transmembrane and extracellular domain, and different amounts of ECSITS as indicated. 
Figure 5. Inhibition of MAPKKK activity by dominant-negative ECSIT $\Delta$. (A) Inhibition of NF- $\mathrm{KB}$ and AP-1 activity induced by MEKK-1 but not NF- $\mathrm{BB}$ activity induced by NIK. MEKK-1 $(0.5 \mu \mathrm{g})$ or NIK $(0.5 \mu \mathrm{g})$ was transfected into $293 \mathrm{kB}$-LUC cells where indicated $(l e f t)$. Alternately, a luciferase reporter vector for AP-1 (AP-1-LUC) was transfected $(0.4 \mu \mathrm{g})$ in all wells (right). ECSITS or vector alone (-) was cotransfected in increasing amounts. Cells were assayed for luciferase activity after $24 \mathrm{hr}$, and the results are reported as RLU/ $\mu$ g of protein. (B) Inhibition of NF-кB and AP-1 activity induced by TRAF6. The experiment was performed similar to $A$, except that $0.5 \mu \mathrm{g}$ of TRAF6 was transfected as indicated.
A

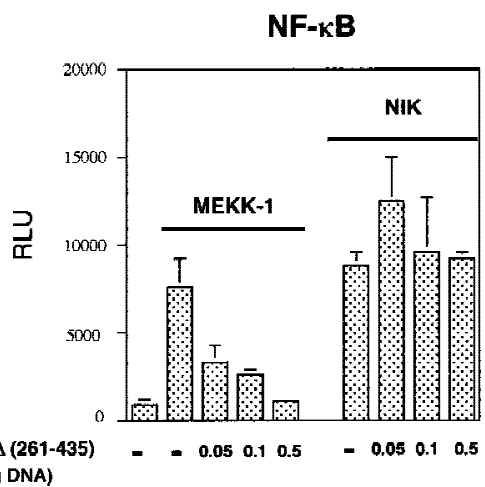

B

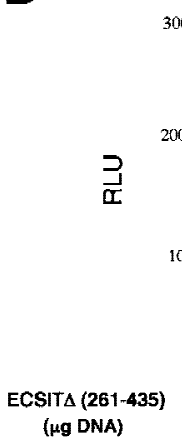

( $\mu \mathrm{g}$ DNA)

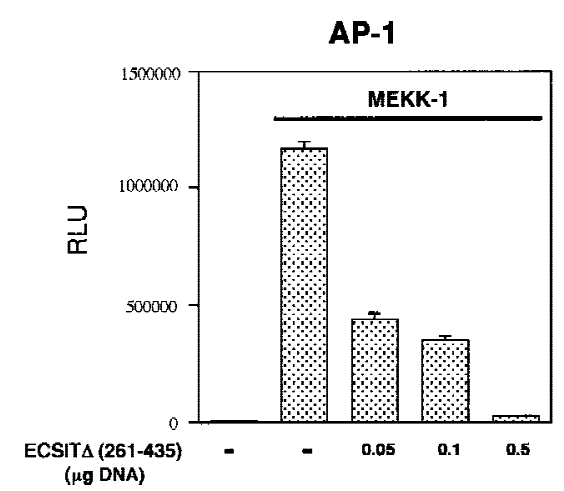

AP-1

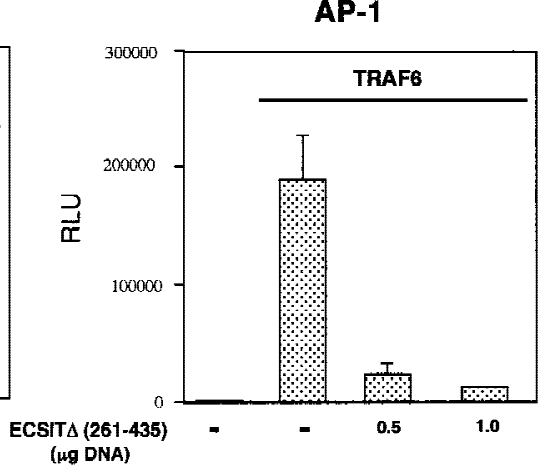

ported previously, we found that NIK does not activate AP-1 and was therefore not assayed in this system (data not shown).

Recently, a kinase of the MAPKKK family, TAB/TAK, has been reported to lie between TRAF6 and NIK (Ninomiya-Tsuji et al. 1999). It has been shown that expression of $\mathrm{TAB} / \mathrm{TAK}$ can activate both NF- $\mathrm{B}$, through NIK, and AP-1, thus suggesting that bifurcation of the signal downstream of TRAF6 occurs via TAB/TAK. However, our results strongly suggested that ECSIT is also involved in signaling to NF- $\mathrm{B}$ and AP-1, thus raising the possibility that there might be branching of pathways downstream of TRAF6 and that at least one pathway includes MEKK-1. To test the importance of ECSIT in TRAF6-mediated activation of both NF- $\mathrm{BB}$ and AP-1, we transfected ECSIT $\Delta$ along with TRAF6 and measured transcriptional activity using luciferase reporter constructs. As shown in Figure 5B, low amounts of ECSIT $\Delta$ were highly effective in inhibiting TRAF6-dependent activation of both these transcription factors. We have also observed inhibition of TRAF6-induced signaling by dominant-negative constructs of MEKK-1 (data not shown). Therefore, these results suggest that ECSIT participates in signaling by TRAF6 and MEKK-1 and provides an alternative means to activate both NF- $\kappa \mathrm{B}$ and AP-1.

\section{ECSIT interacts with $M E K K-1$}

To further investigate the relationship between ECSIT and MEKK-1, we performed immunoprecipitation ex- periments with these two proteins. Remarkably, when ECSIT was cotransfected and expressed in the presence of MEKK-1, a slower migrating form of ECSIT was detected in the lysate (Fig. 6A, left). The upper form of ECSIT can be detected with an antibody specific for the HA epitope tag on ECSIT suggesting that this was a posttranslationally modified form of ECSIT. In immunoprecipitation experiments we have found that MEKK-1 preferentially associated and precipitated this slower migrating form of ECSIT (Fig. 6A, right). The ability of ECSIT $\Delta$ to inhibit MEKK-1 signaling suggested that this truncated protein might also bind MEKK-1. We therefore performed coimmunoprecipitation experiments with FLAG-tagged ECSIT deletion mutants and MEKK-1 and found that, indeed, the ECSIT $\Delta$ mutant interacts with MEKK-1 (Fig. 6B). The ability of the dominant-negative ECSIT mutant to bind MEKK-1 suggests that this binding blocked MEKK-1 signaling.

Because ECSIT appeared as a slower migrating band upon cotransfection with MEKK-1, we explored the possibility that ECSIT could be modified by one of the kinases in the signal transduction pathway, possibly by MEKK-1 itself. To examine this possibility, we cotransfected ECSIT with other known kinases to see if any of these caused the induction of the additional bands. MEKK-1 and the constitutively active kinase domain of MEKK-1, MEKK-1 (described in Lee et al. 1997), but not IRAK, NIK, or kinase-defective MEKK-1 induced the appearance of the slower migrating band [Fig. 6, A /right panel) and C]. Furthermore, we found that cotransfection of ECSIT with TRAF6 also promoted the appearance of 


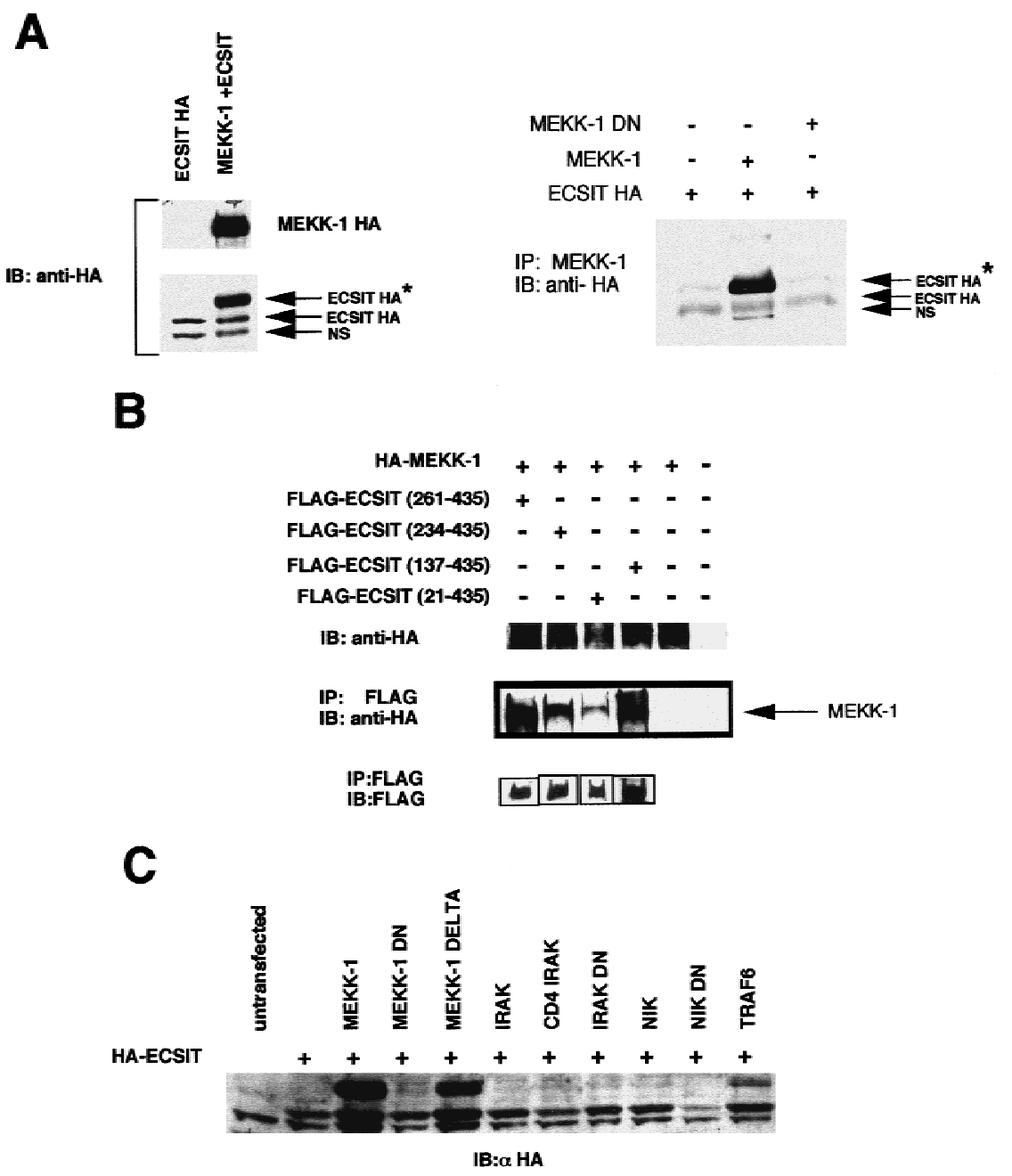

Figure 6. MEKK-1 interacts with ECSIT, and transfection of MEKK-1 with ECSIT induces a post-translational modification of ECSIT. (A) Immunoprecipitation of ECSIT with MEKK-1. 293 cells were transfected with HA-ECSIT, HA-ECSIT, and HA-MEKK-1 (wild type), or HA-ECSIT and HA-MEKK-1 DN, (dominant negative, a point mutant in the kinase domain), and lysates were analyzed by PAGE followed by immunoblotting (left). Alternatively, MEKK-1 was immunoprecipitated from the lysates, and the precipitated proteins were analyzed by PAGE followed by immunoblotting (right). In both instances, immunoblotting was performed using HA antibody (12CA5). (NS) Nonspecific; (Ig) immunoglobulin. The asterisk $\left(^{\star}\right)$ specifies the upshifted ECSIT band that appears upon cotransfection with MEKK-1. (B) ECSIT dominant negative (ECSIT $\Delta$ ) interacts with MEKK-1. 293 cells were cotransfected with Flag-ECSITS, Flag-ECSIT (234-435), Flag-ECSIT (137-435), or FlagECSIT (21-435) and HA-MEKK-1 or HAMEKK-1 alone as indicated. Twenty-four hours after transfection, lysates were made, and a portion of the lysate was used for immunoblotting (IB) with the HA antibody. The rest of the lysate was immunoprecipitated (IP) with Flag (M2) beads and analyzed by SDS-PAGE. Immunoprecipitated proteins were visualized with the HA antibody and with the Flag (M5) antibody. (Bottom) Flag-tagged proteins were expressed and immunoprecipitated in the appropriate samples. $(C)$ Cotransfection of ECSIT with TRAF6 and kinases of the NF$\kappa \mathrm{B}$ signal transduction pathway. HA-ECSIT was cotransfected with the indicated proteins (see Materials and Methods) and analyzed by SDS-PAGE. Gels were immunoblotted with the HA antibody (12CA5). the slower migrating band, although not as effectively as MEKK-1 (Fig. 6C). The inability of the kinase-defective MEKK-1 to induce the appearance of the slower migrating band strongly suggests that the modification is dependent on MEKK-1 kinase activity, but the nature of the modification remains to be fully defined.

\section{ECSIT enhances the processing of MEKK-1}

MEKK-1 is a $195-\mathrm{kD}$ protein that is believed to be activated upon proteolytic cleavage by a caspase (Cardone et al. 1997; Deak et al. 1998). Overexpression of full-length MEKK-1 induces a low amount of cleavage yielding an 80-kD active fragment (extremely low levels of MEKK-1 makes it difficult to examine endogenous MEKK-1 in untransfected cells) (Cardone et al. 1997). This cleaved fragment from transfected MEKK-1 has been visualized previously by immunoblotting with an antibody to the carboxy-terminal region of MEKK-1 (Cardone et al. 1997). We therefore investigated whether ECSIT affected the processing of MEKK-1. ECSIT $\Delta$ or ECSIT wild-type were cotransfected with MEKK-1 and visualized by immunoblotting with either MEKK-1 or ECSIT antibodies (Fig. 7A). The expression of MEKK-1 resulted in the appearance of the characteristic $80-\mathrm{kD}$ active fragment of MEKK-1 (Fig. 7A, lane 3). Coexpression of increasing amounts of ECSIT $\Delta$ completely inhibited the production of this fragment (Fig. 7A, lanes 1,2), whereas coexpression of ECSIT wild type enhanced the production of the 80-kD form of MEKK-1 (Fig. 7A, lanes 4-6). Therefore, the inhibition of MEKK-1-induced activation of NF-кB by ECSIT $\Delta$ correlates with the inhibition of processing of full-length MEKK-1 to the 80-kD form.

If the ECSIT $\Delta$ mutant inhibits MEKK-1 processing, then this mutant should have little effect on NF-кB or AP-1 activity induced by the constitutively active kinase domain of MEKK-1, MEKK-1 $\Delta$. Transcription induced by 
Kopp et al.

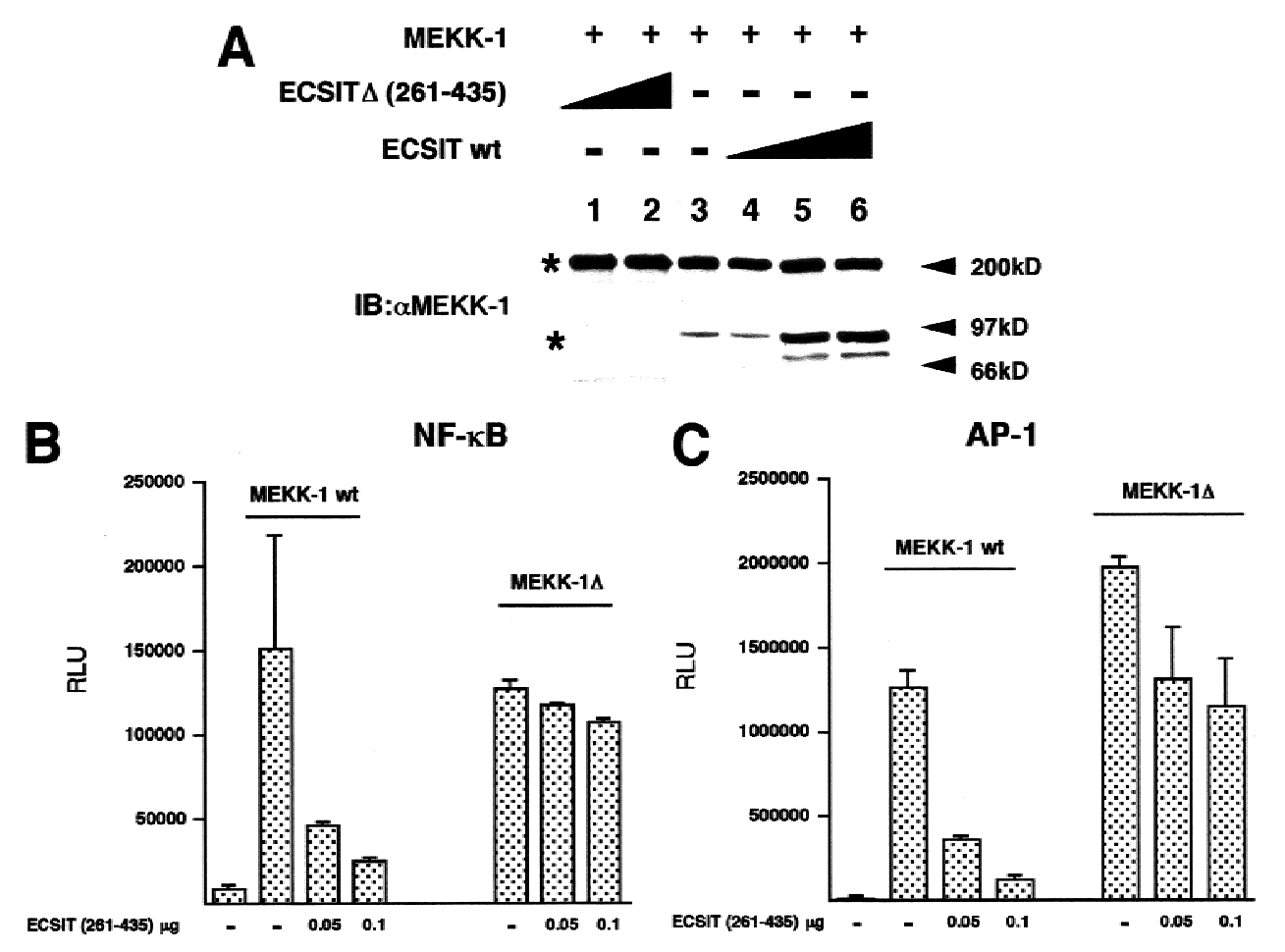

Figure 7. ECSIT induces the processing of MEKK-1, and ECSIT $\Delta$ inhibits this processing. $(A) 293$ cells were transfected with MEKK-1 and vector DNA (lane 3), increasing amounts of ECSIT $\Delta$ (lanes 1,2), or increasing amounts of ECSIT wild type (lanes 4-6). Twenty-four hours after transfection, lysates were prepared and analyzed by SDS-PAGE. Gel was immunoblotted (IB) with an antibody to the carboxyl terminus of MEKK-1. The full-length and processed forms of MEKK-1 are indicated by asterisks $\left({ }^{\star}\right)$. $(B)$ Differential inhibition

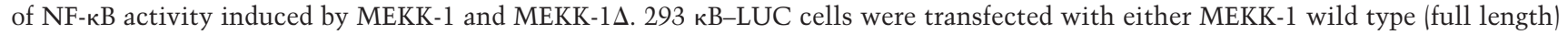
or MEKK- $1 \Delta$ in the presence of increasing amounts of ECSIT $\Delta$ or vector control as indicated. Twenty-four hours after transfection, lysates were prepared and assayed for luciferase activity. $(C)$ Differential inhibition of AP-1 activity induced by MEKK-1 and MEKK-1 $\Delta$. 293 cells were transfected with $0.4 \mu \mathrm{g}$ of AP-1-LUC reporter gene and MEKK-1 wild type (wt) or MEKK-1 $\Delta$, or vector alone as indicated. Twenty-four hours after transfection, lysates were prepared and assayed for luciferase activity.

the MEKK-1 wild-type protein is more sensitive to ECSIT $\Delta$ than transcription induced by MEKK-1s (Fig. $7 \mathrm{~B}, \mathrm{C})$.

\section{Isolation and characterization of Drosophila ECSIT}

In our initial database analysis of the sequence of murine ECSIT, we found Drosophila ESTs homologous to this gene. Because the Toll signaling pathway is conserved in Drosophila, we investigated whether Drosophila ECSIT (dECSIT) was involved in insect host defense responses. We cloned the dECSIT gene by reverse transcriptionpolymerase chain reaction (RT-PCR) using cDNA from Schneider insect cells (Fig. 1C). We then subcloned untagged and Flag-tagged dECSIT wild-type DNAs into a Drosophila expression vector and transfected Schneider cells for immunoprecipitation, transcription reporter assays, and RT-PCR analysis (Fig. 8).

The Drosophila homolog of TRAF6 (dTRAF6) was recently cloned (Liu et al. 1999; R. Medzhitov and C. Janeway, unpubl.). Because ECSIT binds TRAF6 in vertebrate cells, we assayed the ability of dECSIT to bind dTRAF6 by immunoprecipitation. FLAG-tagged dECSIT was cotransfected with V5 epitope-tagged dTRAF6 and subjected to immunoprecipitation with anti-Flag antibody. As expected, dECSIT did interact with dTRAF6 in this assay (Fig. 8A), establishing dECSIT and dTRAF6 as conserved binding partners in a Drosophila system.

To assay the role of dECSIT in insect immunity, we transfected Schneider cells with dECSIT and analyzed the activation of a reporter gene containing the diptericin promoter linked to luciferase (Fig. 8B). This promoter responds to bacterial infection of Drosophila and contains Rel binding sites (Reichart et al. 1992) and can be activated by transfection of dECSIT. We also assayed the production of two antibacterial peptides, defensin and attacin, by RT-PCR (Fig. 8C). Transfection of dECSIT induced the production of these peptides as efficiently as LPS or a dominant-active mutant of the Toll receptor (Toll ${ }^{10 b}$ mutant) (Medzhitov et al. 1997).

\section{Discussion}

We report the identification and characterization of ECSIT, a novel intermediate in Toll/IL-1 signal transduction pathway. ECSIT interacts specifically with TRAF6 and MEKK-1 and appears to function in this pathway by facilitating the processing of MEKK-1. ECSIT 
A

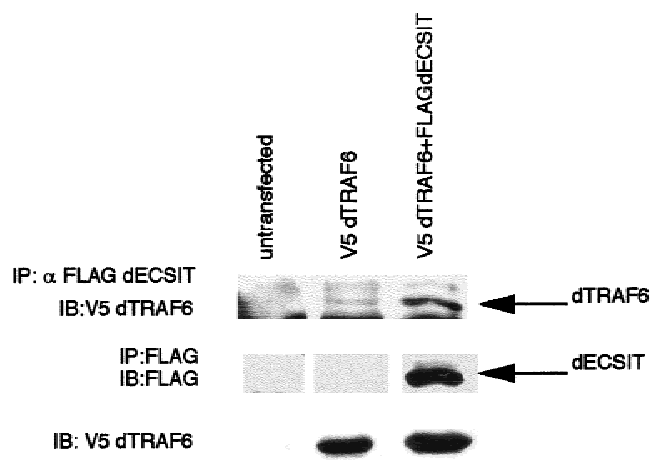

B
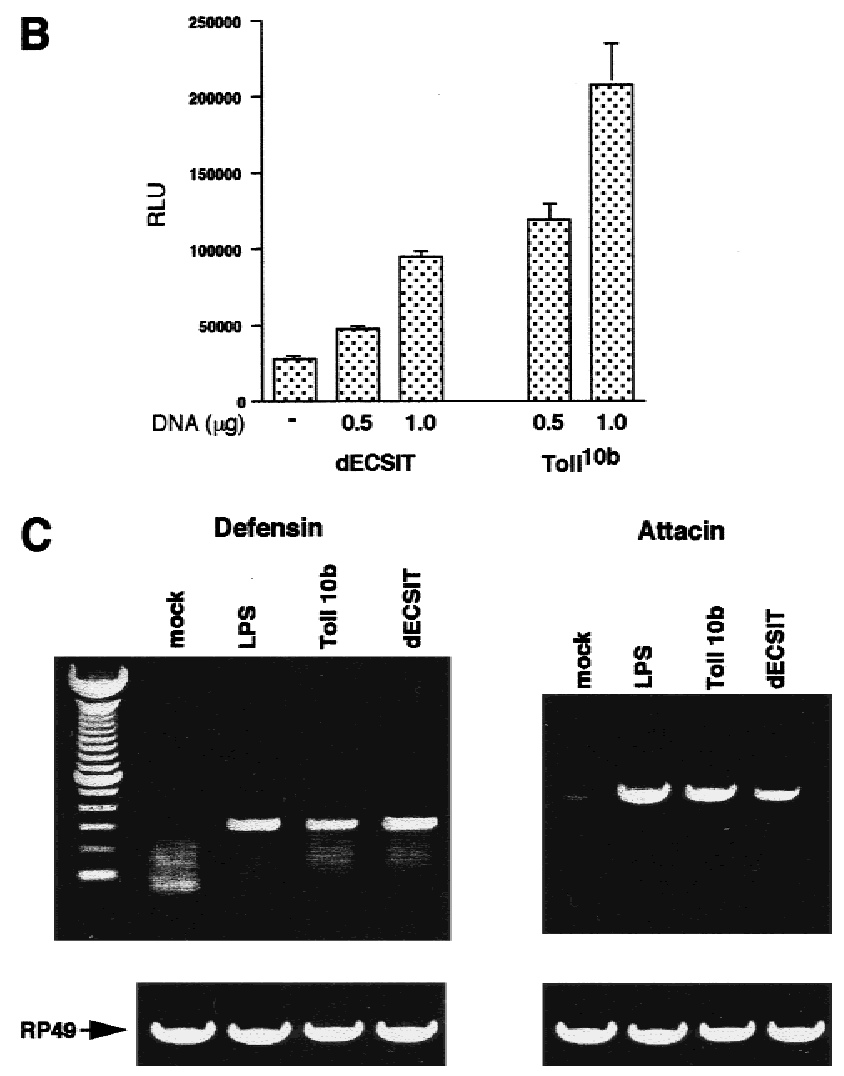

Figure 8. dECSIT plays a role in innate immunity in Drosophila. (A). Association of dECSIT with dTRAF6. Schneider insect cells were untransfected or transfected with V5 epitopetagged dTRAF6 and Flag-tagged dECSIT as indicated. Lysates were prepared after $24 \mathrm{hr}$ and immunoprecipitated with $\alpha$-Flagconjugated beads. Precipitates were analyzed by SDS-PAGE. (B) Activation of the diptericin promoter by dECSIT. Schneider cells were transfected with dECSIT, Toll ${ }^{10 b}$ dominant-active mutant, or vector alone at the concentrations indicated. The diptericin-luciferase promoter was cotransfected in all samples. Thirty-six hours after transfection, lysates were prepared and assayed for luciferase activity. $(C)$ Induction of defensin and attacin peptide transcription by dECSIT. $12 \mathrm{mbn}$ insect cells were transfected with dECSIT, dominant-active Toll ${ }^{10 \mathrm{~b}}$ mutant, or vector. One sample was treated with LPS at $20 \mathrm{ng} / \mathrm{ml}$ as indicated. After $36 \mathrm{hr}$, cDNA was prepared from each sample, and RT-PCR was performed using oligos to RP49 (control, bottom), defensin, or attacin. represents a novel signaling intermediate that not only interacts with multiple components in the pathway but also induces the modification of one of the components, namely MEKK-1. We have also identified and cloned ECSIT from Drosophila and have demonstrated that it performs a similar function in Drosphila cells. Therefore, ECSIT is an evolutionarily conserved signaling adapter protein in the Toll/IL-1 pathway.

The Toll/IL-1 and the TNF receptor signaling pathways have many similarities. Each leads to the activation of the transcription factors NF- $\mathrm{B}$ and, in some cell types, AP-1 (Fig. 9). The overall organization of these pathways is remarkably similar, alternating between adapter proteins and kinases. Despite these similarities, there are important differences. Although both pathways use TRAF adapters and a serine/threonine kinase of the serine/threonine innate immunity kinase (SIIK) type, the specific components in each pathway appear to be distinct. The TNF receptor pathway uses TRAF2, TRAF5, and the RIP kinase, whereas the Toll/IL-1 receptor pathway uses TRAF6 and IRAK (Cao et al. 1996a,b; Muzio et al. 1997; Wesche et al. 1997). Furthermore, whereas TRAF2 interacts with the TNF receptor complex (Rothe et al. 1994; Takeuchi et al. 1996), TRAF6 interacts with IRAK after IL-1 treatment but does not coimmunoprecipitate with the IL-1 receptor complex (Cao et al. 1996b). Unlike the Toll receptor signaling pathway, the TNF receptor pathway has so far not been identified in Drosophila and therefore may have developed after the divergence of vertebrates and invertebrates. ECSIT on the other hand is conserved in Drosophila as dECSIT and specifically binds TRAF6 or dTRAF6 in both vertebrate and invertebrate systems, respectively.

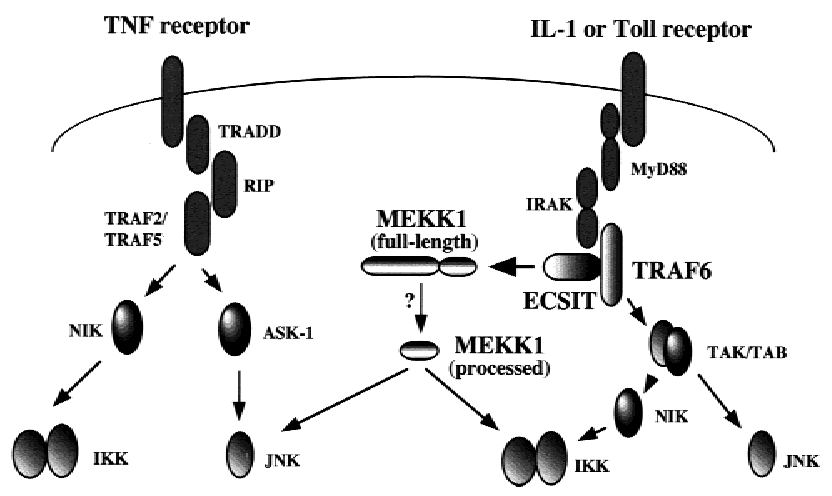

Figure 9. A model of how ECSIT may participate in Toll/IL-1 signaling. The major signaling pathways leading to NF-кB and AP-1 from TNF and IL-1/Toll receptors are indicated. The different proteins indicated do not form multiprotein complexes, probably reflecting the dynamic nature of the signaling pathways; for example, IRAK is rapidly degraded upon signaling. The order of the different proteins in the pathways has been deduced from a combination of experimental approaches, including use of dominant-negative mutants. It is important to note that this figure does not represent the totality of information available about these signaling pathways but is a selective depiction of the key molecules discussed in the paper. 
TRAF6 activates both NF-кB and AP-1 when overexpressed in cells. A necessary upstream event in the activation of these transcription factors is phosphorylation of specific substrates: JNK, in the case of AP-1, and IKKs in the case of NF-кB. Two MAPKKK family members have been shown to interact directly with all of the TRAFs: ASK-1 and NIK. However, neither of these kinases is capable of activating both AP-1 and NF- $\mathrm{kB}$, thus leading to the proposal that the signal transduction pathways bifurcate downstream of the TRAFs. MEKK-1 on the other hand is an attractive candidate for a kinase that bridges the TRAFs to both of these downstream targets, even though MEKK-1 does not appear to interact directly with any of the TRAFs (Natoli et al. 1997). In support of a role for MEKK-1, we have found that TRAF6-induced signaling is inhibited by transfection of very low amounts of dominant-negative MEKK-1 constructs (data not shown). Instead, as our studies show, TRAF6 interacts directly with ECSIT and provides a link to MEKK-1. Because ECSIT appears to bind only TRAF6 and not TRAF2 or TRAF5, MEKK-1 may only participate in TRAF6 signaling. Alternatively, there may be other proteins like ECSIT, which link the other TRAFs to MEKK1. It is important to note that recently a pair of proteins, TAB/TAK, has been suggested to lie downstream of TRAF6 and allows activation of both NF- $\kappa$ B and AP-1, a pathway that appears distinct from the ECSIT/MEKK-1 pathway described here (Ninomiya-Tsuji et al. 1999). It is possible that ECSIT functions similarly to TAB, by acting as an adapter for a downstream MAP3K, which is MEKK-1 for ECSIT and TAK for TAB. The involvement of MEKK-1 in TRAF6 signaling may be determined by the nature of the signal (e.g., Toll signaling vs. CD40 signaling) and does not exclude the possibility that TRAF6 also signals to NF-кB and AP-1 via NIK and ASK1 , respectively.

Although a number of previous studies have implicated MEKK-1 in the activation of NF- $\kappa \mathrm{B}$, its exact role has remained somewhat controversial. MEKK-1 was shown to activate a large multiprotein IкB kinase activity in vitro that could then specifically phosphorylate the NF- $\mathrm{B}$ inhibitor I $\mathrm{B} \alpha$ at the appropriate amino-terminal serine residues (Lee et al. 1997). It was subsequently demonstrated that MEKK-1 could also activate the IкB kinases IKK $\alpha$ and IKK $\beta$ in cells (Lee et al. 1998; Nakano et al. 1998) and that the MEKK-1-inducible kinase activity described above contained IKK $\alpha$ (Lee et al. 1998). The activation of NF-кB by the HTLV-1 transactivating protein, Tax, was also shown to involve MEKK1: It operates by binding to MEKK-1 and stimulating MEKK-1 kinase activity. In addition, a fragment of MEKK-1 copurified in a high-molecular-weight complex containing the functional IKKs (Mercurio et al. 1997), suggesting that MEKK-1 may be a component of IKK complex. Our studies implicating MEKK-1 as a target of ECSIT therefore further strengthen the concept that MEKK-1 plays an important role in signaling to NF-кB.

Expression of ECSIT enhances the processing of MEKK-1 into its smaller $80-\mathrm{kD}$ form, and expression of the carboxy-terminal region of ECSIT appears to inter- fere with this process by binding MEKK-1. An earlier study had suggested that processing of MEKK-1 was only required for the proapoptotic function of MEKK-1 and not for activation of NF-кB or AP-1. However, we have observed a strong correlation between inhibition of the processing of MEKK-1 and inhibition of NF-кB and AP-1. Because the earlier study did not directly examine the role of MEKK-1 in TRAF6-regulated pathways, it is possible that processing of MEKK-1 is associated with NF$\kappa \mathrm{B}$ and AP-1 activation in certain pathways but not others. It is also possible that specific cells used in different studies might be important for the observed differences. It will also be important to fully characterize the mechanism responsible for processing of MEKK-1. Endogenous MEKK-1 is primarily a membrane-associated protein, and hence, processing of MEKK-1 might relocate the kinase domain, thus allowing it to phosphorylate appropriate substrates. Our finding that ECSIT enhances the processing suggests that it might help to recruit a protease (e.g., a caspase) that then cleaves MEKK-1. However, besides its role in facilitating processing of MEKK-1, ECSIT also appears to be important in providing a bridge between TRAF6 and downstream signaling kinases. The mechanism by which TRAFs function in general is unclear, but it is known that they can form oligomers of themselves through the TRAF domain and therefore may assemble higher order functional complexes with other proteins (Arch et al. 1998). Hence, oligomerization of TRAF6 may allow it to recruit additional proteins and link them to MEKK-1 via ECSIT. Alternatively, TRAF6 oligomerization may simply bring MEKK-1 molecules into proximity with other MEKK-1 molecules, allowing cross-phosphorylation, thereby increasing kinase activity.

The mammalian Toll proteins function in innate immune responses. TLR2 and TLR4 have recently been shown to be essential for signal transduction in the cellular response to the bacterial cell-wall component, LPS (Du et al. 1998; Kirschning et al. 1998; Poltorak et al. 1998; Yang et al. 1998; Qureshi et al. 1999|. The innate immune response is conserved in Drosophila where it is responsible for detecting infection and for the subsequent production of antimicrobial peptides to combat it. Genetic studies in Drosophila have revealed that the Rel (or NF-кB) family of transcription factors controls the inducible transcription of many antifungal and antibacterial peptides (Hoffmann et al. 1996). The Toll family of receptors activates these Rel proteins through the sequential activation of cytoplasmic signaling molecules (Kopp and Medzhitov 1999). It is therefore not surprising that the ECSIT homolog in Drosophila (dECSIT) appears to have a role in innate immune function. Recently, two groups of genes, termed immune response deficient (ird), in Drosophila were described that impair either nuclear localization or transcriptional ability of Rel proteins, Dorsal and Dif, suggesting the existence of other, uncharacterized proteins in this pathway (Wu and Anderson 1998). Although still unidentified, these mutants may represent Drosophila homologs of other known members of the vertebrate Toll signaling pathway. The 
recent identification of a Drosophila homolog of TRAF6 supports this concept (Liu et al. 1999). It will be interesting to determine whether one of the ird mutations is in the dECSIT gene.

\section{Materials and methods}

\section{Antibodies and reagents}

Murine TRAF6 antibody was developed in the Ghosh laboratory and is a rabbit polyclonal serum generated against a bacterially expressed GST protein containing the amino-terminal 100 amino acids of murine TRAF6. Antibodies to MEKK-1 (C-22), $\mathrm{I \kappa} B \alpha(\mathrm{C}-21)$, TRAF2 (N-19), and TRAF5 (N-20) are from Santa Cruz Biotechnology, Inc. HA antibody is a mouse monoclonal expressed from 12CA5 cells. Flag antibody (M5) and conjugated Flag (M2) affinity beads are from Sigma. V5 monoclonal antibody is from Invitrogen.

\section{Plasmids}

HA wild-type and kinase-defective rat MEKK-1 were a kind gift of Dr. Melanie Cobb (University of Texas Southwestern Medical Center, Dallas). The Drosophila expression vector pJL1 was a gift of Dr. Jules Hoffmann (Institute of Molecular and Cellular Biology CNRS, Strasbourg, France). The diptericin promoter luciferase reporter vector was a generous gift of Dr. Jean-Marc Reichart (Institute of Molecular and Cellular Biology CNRS, Strasbourg, France). NIK and NIK dominant-negative were gifts of D. Wallach (Weizmann Institute, Rehovot, Israel). The AP-1 luciferase reporter (AP-1LUC) and the NF- $\mathrm{KB}$ reporter pBIIx-luciferase have been described previously.

\section{Cloning of ECSIT by yeast two-hybrid assay}

A yeast two-hybrid cDNA library was constructed from mouse liver using the Hybri-ZAP two-hybrid cDNA gigapack cloning kit (Stratagene). The library was mass excised into the activation domain vector pADGAL4 according to manufacturer's instructions. Murine TRAF6 was cloned from a mouse pre-B-cell library by hybridization screening. The complete open reading frame encoding 530 amino acids was subcloned in-frame into the yeast DNA-binding domain vector pBDGAL4 (Stratagene) and used for library screening. Positive clones were identified by $\beta$-galactosidase assay on colonies grown on $\mathrm{Trp}^{-}, \mathrm{Leu}^{-}, \mathrm{His}^{-}$ medium. Two positive clones were isolated and sequenced and were found to be identical $1.2-\mathrm{kb}$ cDNAs.

\section{cDNA cloning and Northern blot hybridization}

The 1.2-kb fragment isolated from yeast two-hybrid screening was labeled with $\left[\alpha-{ }^{32} \mathrm{P}\right] \mathrm{dCTP}$ using the Prime-It-II random priming kit (Stratagene). Northern blot hybridization screening was performed according to manufacturer's instructions on a Clontech multiple tissue Northern blot. The mouse liver cDNA library was from Clontech. The pre-B-cell library was described previously (Thompson et al. 1995). Plaques $\left(1 \times 10^{6}\right)$ from each library were screened by hybridization using reagents and protocol from Clontech. DNA from positive plaques was subcloned into either pcDNA3 (Invitrogen) or pCIneo (Promega) and sequenced. The source for the EST sequences used for identifying the dTRAF6 and dECSIT was the Berkeley Drosophila Genome Project.

\section{Construction of expression plasmids}

Murine IRAK and murine TRAF6 were cloned from a mouse
pre-B-cell library by hybridization screening. The IRAK sequence corresponds to the published murine 'Pelle-like kinase' but is full length and includes another 20 amino acids at the amino terminus (GenBank accession no. AF103876). Murine TRAF2 and TRAF5 were cloned by RT-PCR. Deletion mutants of ECSIT, IRAK, and TRAF6 were constructed by inserting PCR-amplified DNA fragments into the pCI-neo expression vector (Promega). Murine MEKK-1 $\Delta$ was obtained by hybridization screening of a mouse pre-B-cell library followed by PCR with Pfu (Stratagene) polymerase to obtain the carboxy-terminal active kinase fragment described previously (Lee et al. 1997). Flag epitope-tagged constructs were made by subcloning PCRamplified DNAs into the pFlag-CMV2 expression vector (Kodak). HA epitope-tagged constructs were made by PCR amplification of DNAs using a 5' HA sequence as follows: ATGGACTACCCCTACGACGTCCCCGACTACGCC except for HAECSIT in which the epitope tag is at the carboxyl terminus. Drosophila expression vectors were constructed by subcloning epitope-tagged cDNAs into the vector pJL1 (J. Hoffmann laboratory) or the vector pAc5.1/V5-His (Invitrogen).

\section{Cell lines and stable transfectants}

Human 293 cells were cultured in DMEM, 7\% fetal calf serum (Gemini), Pen/Strep (Life Technologies), and glutamine (Life Technologies). The stable cell line $293 \mathrm{kB}-\mathrm{LUC}$ was made by cotransfecting the NF-кB reporter gene pBIIxLUC (Kopp and Ghosh 1994) and the plasmid pCI-neo (Promega) (at a ratio of 10:1, respectively) into 293 cells using Lipofectamine (GIBCO $\mathrm{BRL}$, manufacturer's instructions). Stable transfectants were selected with G418 (Life Technologies) at $1.6 \mathrm{mg} / \mathrm{ml}$. Positive clones were assayed by treatment of cells for $5 \mathrm{hr}$ with IL-1 $\beta$ (human recombinant, Genzyme) followed by luciferase assay (Promega). The cell line used was stimulated $\sim 100$-fold in this assay.

\section{Luciferase reporter assays}

293 or $293 \mathrm{kB}-\mathrm{LUC}$ cells are split to $30 \%$ confluence in 6-well dishes $24 \mathrm{hr}$ before transfection. Cells are typically transfected with a total of $2 \mu \mathrm{g}$ of DNA per well with the transfection reagent Fugene at $3 \mu \mathrm{l}$ of reagent per microgram of DNA according to manufacturer's instructions. Cells were transfected with either pBIIxLUC (Kopp and Ghosh 1994) or AP-1-LUC (Rincon and Flavell 1994) constructs 24 hr later; cells are collected, washed once with PBS, and lysed in $150 \mu 1$ of TNT $(20 \mathrm{~mm}$ Tris at $\mathrm{pH} 8.0,150 \mathrm{~mm} \mathrm{NaCl}, 1 \%$ Triton X-100) containing aprotinin, leupeptin, PMSF, and pepstatin. Five microliters of lysate is assayed in $50 \mu \mathrm{l}$ of substrate (Promega), and light units are measured in a LUMAT luminometer. Activation of NF-кB by ECSIT wild type (Fig. 3) was performed in $293 \mathrm{kB}$-LUC cells in which background (untransfected) was subtracted and luciferase units relative to micrograms of protein are represented. Graphs shown are representative examples of assays performed in duplicate or triplicate and repeated at least three times. Inhibition studies were performed by cotransfecting increasing amounts of Flag-tagged ECSIT $\Delta$ DNA and a constant amount of inducer construct DNA.

\section{Transfections and immunoprecipitation}

For in vitro precipitation with GST fusion proteins, DNAs were subcloned into the bacterial expression vector pGEX6P-1 (Pharmacia) in-frame. Bacteria (BL-21 strain) were transformed with DNA and induced with IPTG $(0.1 \mathrm{~mm})$ for 2-24 hr. Bacteria were collected and resuspended in $10 \%$ of the original volume of PBS 
and treated with lysozyme to $1 \mathrm{mg} / \mathrm{ml}$ at room temperature for 30 min. Triton X-100 was then added to $1 \%$, and samples were sonicated for $1.5 \mathrm{~min}$. Lysates were then centrifuged at $30,000 \mathrm{~g}$ in a Sorvall centrifuge. Supernatants containing $\sim 2 \mu \mathrm{g}$ of GST protein were incubated with ${ }^{35} \mathrm{~S}$-labeled, in vitro translated proteins (T7 Quick kit, Promega) and $30 \mu$ of glutathione-Sepharose $4 \mathrm{~B}$ beads suspended 1:1 in TNT for $2 \mathrm{hr}$ at $4^{\circ} \mathrm{C}$. Beads were centrifuged and washed with TNT four times. Beads were resuspended in SDS-containing buffer, and proteins were separated by SDS-PAGE. Gels were amplified with Amplify (Amersham), dried, and exposed to film. Proteins were transferred to Immobilon-P membrane and blotted with specific antibodies.

\section{Acknowledgments}

We acknowledge Dr. Mark Solomon and David Schatz for carefully reviewing our paper. S.G. is an Associate Investigator of the Howard Hughes Medical Institute. This work was funded by the HHMI and the National Institutes of Health (RO1-AI4334).

The publication costs of this article were defrayed in part by payment of page charges. This article must therefore be hereby marked 'advertisement' in accordance with 18 USC section 1734 solely to indicate this fact.

\section{References}

Arch, R.H., R.W. Gedrich, and C.B. Thompson. 1998. Tumor necrosis factor receptor-associated factors (TRAFs)-A family of adapter proteins that regulates life and death. Genes \& Dev. 12: 2821-2830.

Belvin, M.P. and K.V. Anderson. 1996. A conserved signaling pathway: The Drosophila toll-dorsal pathway. Annu. Rev. Cell Dev. Biol. 12: 393-416.

Cao, Z., W.J. Henzel, and X. Gao. 1996a. IRAK: A kinase associated with the interleukin-1 receptor. Science 271: 11281131.

Cao, Z., J. Xiong, M. Takeuchi, T. Kurama, and D.V. Goeddel. 1996b. TRAF6 is a signal transducer for interleukin-1. Nature 383: 443-446.

Cardone, M.H., G.S. Salvesen, C. Widmann, G. Johnson, and S.M. Frisch. 1997. The regulation of anoikis: MEKK-1 activation requires cleavage by caspases. Cell 90:315-323.

Chaudhary, P.M., C. Ferguson, V. Nguyen, O. Nguyen, H.F. Massa, M. Eby, A. Jasmin, B.J. Trask, L. Hood, and P.S. Nelson. 1998. Cloning and characterization of two Toll/Interleukin-1 receptor-like genes TIL3 and TIL4: Evidence for a multi-gene receptor family in humans. Blood 91: 4020-4027.

Cohen, L., W.J. Henzel, and P.A. Baeuerle. 1998. IKAP is a scaffold protein of the ІкB kinase complex. Nature 395: 292-296.

Deak, J.C., J.V. Cross, M. Lewis, Y. Qian, L.A. Parrott, C.W. Distelhorst, and D.J. Templeton. 1998. Fas-induced proteolytic activation and intracellular redistribution of the stresssignaling kinase MEKK1. Proc. Natl. Acad. Sci. 95: 55955600.

Drier, E.A. and R. Steward. 1997. The dorsoventral signal transduction pathway and the Rel-like transcription factors in Drosophila. Semin. Cancer Biol. 8: 83-92.

Du, X., P. Thompson, E.K.L. Chan, J. Ledesma, B. Roe, S. Clifton, S.N. Vogel, and B. Beutler. 1998. Genetic and physical mapping of the lps locus: Identification of the Toll-4 receptor as a candidate gene in the critical region. Blood Cells Mol. Dis. 24: 340-355.

Galindo, R.L., D.N. Edwards, S.K.H. Gillespie, and S.A. Wasserman. 1995. Interaction of the pelle kinase with the mem- brane-associated protein tube is required for transduction of the dorsalventral signal in Drosophila embryos. Development 121: 2209-2218.

Ghosh, S., M.J. May, and E.B. Kopp. 1998. NF-кB and Rel proteins: Evolutionarily conserved mediators of immune responses. Annu. Rev. Immunol. 16: 225-260.

Greenfeder, S.A., P. Nunes, L. Kwee, M. Labow, R.A. Chizzonite, and G. Ju. 1995. Molecular cloning and characterization of a second subunit of the interleukin 1 receptor complex. $J$. Biol. Chem. 270: 13757-13765.

Hoffmann, J.A., J.-M. Reichhart, and C. Hetru. 1996. Innate immunity in higher insects. Curr. Opin. Immunol. 8: 8-13.

Ishida, T., S. Mizushima, S. Azuma, N. Kobayashi, T. Tojo, K. Suzuki, S. Aizawa, T. Watanabe, G. Mosialos, E. Kieff, T. Yamamoto, and J. Inoue. 1996. Identification of TRAF6, a novel tumor necrosis factor receptor-associated factor protein that mediates signaling from an amino-terminal domain of the CD40 cytoplasmic region. J. Biol. Chem. 271: 2874528748.

Kirschning, C.J., H. Wesche, T. Merrill Ayres, and M. Rothe. 1998. Human toll-like receptor 2 confers responsiveness to bacterial lipopolysaccharide. J. Exp. Med. 188: 2091-2097.

Kopp, E. and S. Ghosh. 1994. Inhibition of NF-кB by sodium salicylate and aspirin. Science 265: 956-959.

Kopp, E.B. and R. Medzhitov. 1999. The Toll-receptor family and control of innate immunity. Curr. Opin. Immunol. 11: $13-18$

Lee, F.S., J. Hagler, Z.J. Chen, and T. Maniatis. 1997. Activation of the IкB $\alpha$ kinase complex by MEKK1, a kinase of the JNK pathway. Cell 88: 213-222.

Lee, F.S., R.T. Peters, L.C. Dang, and T. Maniatis. 1998. MEKK1 activates both ІкB kinase $\alpha$ and ІкB kinase $\beta$. Proc. Natl. Acad. Sci. 95: 9319-9324.

Lemaitre, B., J.M. Reichhart, and J.A. Hoffmann. 1997. Drosophila host defense: Differential induction of antimicrobial peptide genes after infection by various classes of microorganisms. Proc. Natl. Acad. Sci. 94: 14614-14619.

Liu, H., Y.C. Su, E. Becker, J. Treisman, and E.Y. Skolnik. 1999. A Drosophila TNF-receptor-associated factor (TRAF) binds the ste20 kinase Misshapen and activates Jun kinase. Curr. Biol. 9: 101-104.

Liu, Z.G., H. Hsu, D.V. Goeddel, and M. Karin. 1996. Dissection of TNF receptor 1 effector functions: JNK activation is not linked to apoptosis while NF-кB activation prevents cell death. Cell 87: 565-576.

Malinin, N.L., M.P. Boldin, A.V. Kovalenko, and D. Wallach. 1997. MAP3K-related kinase involved in NF-кB induction by TNF, CD95 and IL-1. Nature 385: 540-544.

May, M.J. and S. Ghosh. 1998. Signal transduction through NFкB. Immunol. Today 19: 80-88.

Medzhitov, R., P. Preston-Hurlburt, and C.A. Janeway Jr. 1997. A human homologue of the Drosophila Toll protein signals activation of adaptive immunity. Nature 388: 394-397.

Medzhitov, R., P. Preston-Hurlburt, E. Kopp, A. Stadlen, C. Chen, S. Ghosh, and C.A. Janeway Jr. 1998. MyD88 is an adaptor protein in the hToll/IL-1 receptor family signaling pathways. Mol. Cell 2: 253-258.

Mercurio, F., H. Zhu, B.W. Murray, A. Shevchenko, B.L. Bennett, J.W. Li, D.B. Young, M. Barbosa, M. Mann, A. Manning, and A. Rao. 1997. IKK-1 and IKK-2: Cytokine-activated ІкB kinases essential for NF-кB activation. Science 278: 860866.

Muzio, M., J. Ni, P. Feng, and V.M. Dixit. 1997. IRAK (Pelle) family member IRAK-2 and MyD88 as proximal mediators of IL-1 signaling. Science 278: 1612-1615.

Muzio, M., G. Natoli, S. Saccani, M. Levrero, and A. Mantovani. 
1998. The human toll signaling pathway: Divergence of nuclear factor $\mathrm{\kappa B}$ and JNK/SAPK activation upstream of tumor necrosis factor receptor-associated factor 6 (TRAF6). J. Exp. Med. 187: 2097-2101.

Nakano, H., M. Shindo, S. Sakon, S. Nishinaka, M. Mihara, H. Yagita, and K. Okumura. 1998. Differential regulation of ІкB kinase alpha and beta by two upstream kinases, NF-кB-inducing kinase and mitogen-activated protein kinase/ERK kinase kinase-1. Proc. Natl. Acad. Sci. 95: 3537-3542.

Natoli, G., A. Costanzo, F. Moretti, M. Fulco, C. Balsano, and M. Levrero. 1997. Tumor necrosis factor (TNF) receptor 1 signaling downstream of TNF receptor-associated factor 2 . Nuclear factor kappaB (NFkB)-inducing kinase requirement for activation of activating protein 1 and NFкB but not of c-Jun $\mathrm{N}$-terminal kinase/stress-activated protein kinase. I. Biol. Chem. 272: 26079-26082.

Ninomiya-Tsuji, J., K. Kishimoto, A. Hiyama, J. Inoue, Z. Cao, and K. Matsumoto. 1999. The kinase TAK1 can activate the NIK-IкB as well as the MAP kinase cascade in the IL-1 signalling pathway. Nature 398: 252-256.

Nishitoh, H., M. Saitoh, Y. Mochida, K. Takeda, H. Nakano, M. Rothe, K. Miyazono, and H. Ichijo. 1998. ASK1 is essential for JNK/SAPK activation by TRAF2. Mol. Cell 2: 389-395.

Poltorak, A., X. He, I. Smirnova, M.Y. Liu, C.V. Huffel, X. Du, D. Birdwell, E. Alejos, M. Silva, C. Galanos, M. Freudenberg, P. Ricciardi-Castagnoli, B. Layton, and B. Beutler. 1998. Defective LPS signaling in $\mathrm{C} 3 \mathrm{H} / \mathrm{HeJ}$ and $\mathrm{C} 57 \mathrm{BL} / 10 \mathrm{ScCr}$ mice: Mutations in Tlr4 gene. Science 282: 2085-2088.

Qureshi, S.T., L. Lariviere, G. Leveque, S. Clermont, K.J. Moore, P. Gros, and D. Malo. 1999. Endotoxin-tolerant mice have mutations in Toll-like receptor 4 (Tlr4). J. Exp. Med. 189: 615-625.

Reichhart, J.M., M. Meister, J.L. Dimarcq, D. Zachary, D. Hoffmann, C. Ruiz, G. Richards, and J.A. Hoffmann. 1992. Insect immunity: Developmental and inducible activity of the Drosophila diptericin promoter. EMBO J. 11: 1469-1477.

Rincon, M. and R.A. Flavell. 1994. AP-1 transcriptional activity requires both $\mathrm{T}$-cell receptor-mediated and co-stimulatory signals in primary T lymphocytes. EMBO J. 13: 4370-4381.

Rock, F.L., G. Hardiman, J.C. Timans, R.A. Kastelein, and J.F. Bazan. 1998. A family of human receptors structurally related to Drosophila Toll. Proc. Natl. Acad. Sci. 95: 588-593.

Rothe, M., S.C. Wong, W.J. Henzel, and D.V. Goeddel. 1994. A novel family of putative signal transducers associated with the cytoplasmic domain of the $75 \mathrm{kDa}$ tumor necrosis factor receptor. Cell 78: 681-692.

Rothwarf, D.M., E. Zandi, G. Natoli, and M. Karin. 1998. IKK- $\gamma$ is an essential regulatory subunit of the IкB kinase complex. Nature 395: 297-300.

Sims, J.E., C.J. March, D. Cosman, M.B. Widmer, H.R. MacDonald, C.J. McMahan, C.E. Grubin, J.M. Wignall, J.L. Jackson, S.M. Call et al. 1988. cDNA expression cloning of the IL-1 receptor, a member of the immunoglobulin superfamily. Science 241: 585-589.

Song, H.Y., C.H. Regnier, C.J. Kirschning, D.V. Goeddel, and M. Rothe. 1997. Tumor necrosis factor (TNF)-mediated kinase cascades: Bifurcation of nuclear factor-kappaB and c-jun $\mathrm{N}$ terminal kinase (JNK/SAPK) pathways at TNF receptor-associated factor 2. Proc. Nat1. Acad. Sci. 94: 9792-9796.

Stanger, B.Z., P. Leder, T.H. Lee, E. Kim, and B. Seed. 1995. RIP; A novel protein containing a death domain that interacts with Fas/APO-1 (CD95) in yeast and causes cell death. Cell 81: 513-523.

Takeuchi, M., M. Rothe, and D.V. Goeddel. 1996. Anatomy of TRAF2. Distinct domains for nuclear factor-kappaB activation and association with tumor necrosis factor signaling proteins. J. Biol. Chem. 271: 19935-19942.

Thompson, J.E., R.J. Phillips, H. Erdjument-Bromage, P. Tempst, and S. Ghosh. 1995. IкB $\beta$ regulates the persistent response in a biphasic activation of NF-кB. Cell 80: 573-582.

Torigoe, K., S. Ushio, T. Okura, S. Kobayashi, M. Taniai, T. Kunikata, T. Murakami, O. Sanou, H. Kojima, M. Fujii, T. Ohta, M. Ikeda, H. Ikegami, and M. Kurimoto. 1997. Purification and characterization of the human interleukin-18 receptor. J. Biol. Chem. 272: 25737-25742.

Towb, P., R.L. Galindo, and S.A. Wasserman. 1998. Recruitment of Tube and Pelle to signaling sites at the surface of the Drosophila embryo. Development 125: 2443-2450.

Wesche, H., W.J. Henzel, W. Shillinglaw, S. Li, and Z. Cao. 1997. MyD88: An adapter that recruits IRAK to the IL-1 receptor complex. Immunity 7: 837-847.

Wu, L.P. and K.V. Anderson. 1998. Regulated nuclear import of Rel proteins in the Drosophila immune response. Nature 392: 93-97.

Yamaoka, S., G. Courtois, C. Bessia, S.T. Whiteside, R. Weil, F. Agou, H.E. Kirk, R.J. Kay, and A. Israel. 1998. Complementation cloning of NEMO, a component of the IkappaB kinase complex essential for NF-kappaB activation. Cell 93: 12311240.

Yang, R.B., M.R. Mark, A. Gray, A. Huang, M.H. Xie, M. Zhang, A. Goddard, W.I. Wood, A.L. Gurney, and P.J. Godowski. 1998. Toll-like receptor-2 mediates lipopolysaccharide-induced cellular signalling. Nature 395: 284-288. 


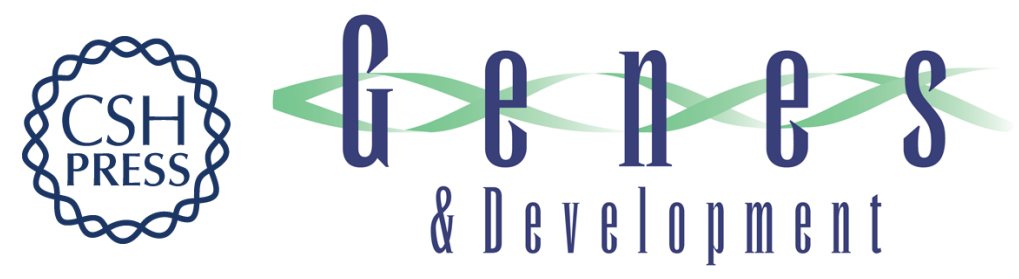

\section{ECSIT is an evolutionarily conserved intermediate in the Toll/IL-1 signal transduction pathway}

Elizabeth Kopp, Ruslan Medzhitov, James Carothers, et al.

Genes Dev. 1999, 13:

References This article cites 52 articles, 24 of which can be accessed free at:

http://genesdev.cshlp.org/content/13/16/2059.full.html\#ref-list-1

License

Email Alerting Receive free email alerts when new articles cite this article - sign up in the box at the top Service right corner of the article or click here.

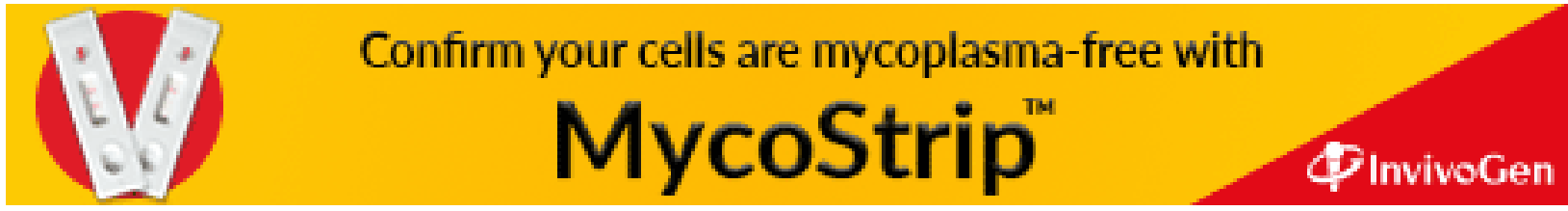

